\title{
Ventricular Assist Devices in Heart Failure: How to Support the Heart but Prevent Atrophy?
}

\author{
M. POKORNÝ ${ }^{1,3}$, L. ČERVENKA ${ }^{2,3}$, I. NETUKA ${ }^{1,4}$, J. PIRK $^{1}$, M. KOŇǍ̌́Í ${ }^{1}$, J. MALÝ $^{1}$ \\ ${ }^{1}$ Department of Cardiovascular Surgery, Institute for Clinical and Experimental Medicine, Prague, \\ Czech Republic, ${ }^{2}$ Center for Experimental Medicine, Institute for Clinical and Experimental \\ Medicine, Prague, Czech Republic, ${ }^{3}$ Second Faculty of Medicine, Charles University and \\ University Hospital Motol, Prague, Czech Republic, ${ }^{4}$ Second Department of Surgery, Department \\ of Cardiovascular Surgery, First Faculty of Medicine, Charles University in Prague, Prague, Czech \\ Republic
}

Received July 16, 2013

Accepted November 8, 2013

\begin{abstract}
Summary
Ventricular assist devices (VAD) have recently established themselves as an irreplaceable therapeutic modality of terminal heart failure. Because of the worldwide shortage of donors, ventricular assist devices play a key role in modern heart failure therapy. Some clinical data have revealed the possibility of cardiac recovery during VAD application. On the other hand, both clinical and experimental studies indicate the risk of the cardiac atrophy development, especially after prolonged mechanical unloading. Little is known about the specific mechanisms governing the unloading-induced cardiac atrophy and about the exact ultrastructural changes in cardiomyocytes, and even less is known about the ways in which possible therapeutical interventions may affect heart atrophy. One aim of this review was to present important aspects of the development of VADrelated cardiac atrophy in humans and we also review the most significant observations linking clinical data and those derived from studies using experimental models. The focus of this article was to review current methods applied to alleviate cardiac atrophy which follows mechanical unloading of the heart. Out of many pharmacological agents studied, only the selective beta2 agonist clenbuterol has been proved to have a significantly beneficial effect on unloading-induced atrophy. Mechanical means of atrophy alleviation also seem to be effective and promising.
\end{abstract}

\section{Key words}

Ventricular assist devices - Cardiac - Heart - Atrophy • Mechanical unloading • Clenbuterol • Experimental models • Heterotopic heart transplantation

\section{Corresponding author}

M. Pokorný, Department of Cardiovascular Surgery, Institute for Clinical and Experimental Medicine, Vídeňská 1958/9, Prague 4, 140 00, Czech Republic. Fax: +420 236052 776. E-mail: mpok@ikem.cz

\section{Introduction}

Heart failure represents a complex disorder influencing cardiac structure, function, biochemistry, and gene expression (Mann and Bristol 2005). Heart muscle cells are, due to cardiac plasticity, very sensitive to any changes in load or systemic neurohormonal activation. The process of cardiac remodeling can be either physiological (growth of an organism, physical exercise etc.) or pathological, where various noxious stimuli can start the vicious cycle of progressive myocardial dysfunction terminating in heart failure (Cohn et al. 2000). Due to the increasing prevalence of chronic heart failure, it was essential to develop new therapeutic measures in addition to heart transplantation.

The first introduction of a ventricular assist device (VAD) in the 1960s by DeBakey represented 
a turning point in terminal heart failure therapy. In the 1990s, VADs became a well-established treatment as a bridge to transplantation - treatment of patients with end-stage heart failure awaiting heart transplantation. Long-term mechanical support also started to be used as a destination therapy - therapeutic measure per se in patients ineligible for heart transplantation (DeBakey 2000). Meanwhile the improvement in cardiac function in patients on VADs was recognized (Frazier et al. 1996). Newer clinical data proved that VAD therapy was able to provide myocardial recovery, thanks to a process described as the reverse remodeling (Birks et al. 2011). Reaching persistent myocardial recovery after VAD weaning in patients with advanced heart failure is one of the most sought-after targets in recent heart disease treatment (Drakos et al. 2011a). Despite intense scientific research, there are still many obstacles that prevent us from achieving the desired sustained recovery (Butler et al. 2012). The development of cardiac atrophy after mechanical unloading plays a significant role impacting sustained recovery.

\section{Heart atrophy and ventricular assist devices}

Initially the heart atrophy-acquired reduction in the size and mass was described morphologically and main diagnostic criteria were based on decreased weight, increased pigmentation, subepicardial fat atrophy, tortuosity of coronary arteries and increase of nuclei/muscle fiber ratio (Hellerstein and SantiagoStevenson 1950).

Cardiac atrophy develops after hemodynamic or metabolic unloading of the heart. Cardiac atrophic remodeling is a rapid response to many different stimuli such as VAD therapy, prolonged bed rest, starvation, cancer cachexia, chronic infection, or even spaceflight (Hellerstein and Santiago-Stevenson 1950, Perhonen et al. 2001). Cardiac plasticity is a process based on rapid protein synthesis or degradation control, which allows quick adaptation to ongoing stimuli. Depending on the type of stimulus, atrophic or hypertrophic changes may prevail. In other words, atrophy is defined as a shift in the balance of protein turnover in favor of proteolysis. According to the stimulus intensity and duration, reversible or irreversible changes may develop (Baskin and Taegtmeyer 2011). Despite the great clinical importance of atrophic remodeling, very little is currently known about mechanisms governing the atrophic process. Sporadic observations point out the ubiquitin proteosome proteolytic pathway as possible executive mechanism in cardiac atrophy connected with mechanical unloading of the heart. Ubiquitin proteosome proteolytic pathway is responsible for the major part of protein degradation and it was found to be upregulated early after the heart unloading (Razeghi et al. 2003). In accordance with previous finding there was also observed activation of the calpain system (group of endopeptidases that disintegrate myofibrilar proteins and present them to the ubiquitin proteasome system) which may regulate cell signaling to favor the atrophy (Razeghi et al. 2007). Later studies revealed the muscle ring finger 1 as another important regulatory protein which is up regulated after ventricular unloading and in turn responsible for cardiac atrophy development (Willis et al. 2009). Novel observation found a significant activation of the $\mathrm{FoxO} 3$ transcription factor, an established regulator of catabolic processes in other cell types. FoxO3 activation by mechanical unloading governs both the autophagy-lysosomal and ubiquitin-proteasome system to inflict cardiac atrophy (Cao et al. 2013).

\section{Heart atrophy associated with VADs in humans}

When mechanical cardiac support is used during the treatment of terminal heart failure, beneficial changes in the myocardium predominate (reverse remodeling). Numerous clinical trials have consistently attested to improvement in pathological cardiac hypertrophy, calcium homeostasis, enhancement of beta-adrenergic signaling, and electrophysiologic remodeling. At this point, another puzzling question which emerges is how contractile performance can be improved to match the reduction of ventricular mass and cardiomyocyte size (DeBakey 2000, Heerdt et al. 2000, Terracciano et al. 2003, Rodrigue-Way et al. 2005, Drakos et al. 2007, 2011b)?

According to the latest findings, VADassociated cardiac functional recovery is closely linked to alterations in several key areas including cell survival, energy metabolism, adrenergic receptor signaling, and especially calcium handling (Terracciano et al. 2004, Klotz et al. 2008, Soppa et al. 2008, Ogletree et al. 2010, Felkin et al. 2011, Ibrahim et al. 2012, Mann et al. 2012).

Nevertheless, some changes that occur after mechanical unloading are maladaptive in nature, as it has been demonstrated in a limited number of clinical studies. Disuse atrophy of a previously hypertrophied ventricle is 
potentially an important limiting factor in attempts to achieve myocardial recovery in treatment strategies using VADs (Maybaum et al. 2007).

\section{Unloading studies in experimental models}

As the need grows for a deeper understanding of the mechanisms that govern reverse remodeling, experimental models come into play due to the limitations of clinical trials. Heterotopic transplantation of the mammalian heart represents a well-established model of mechanical heart unloading. First introduced in 1933 in dogs (Mann et al. 1933), heterotopic transplantation (Fig. 1) was later performed in rats (Abott et al. 1964) and thereafter in mice (Corry et al. 1973). In particular, thanks to later modifications of the surgical technique and especially to the information gained from transplantations of failing hearts, the differences in changes following normal versus failed heart unloading were uncovered (Ruzza et al. 2010, Ibrahim et al. 2013).

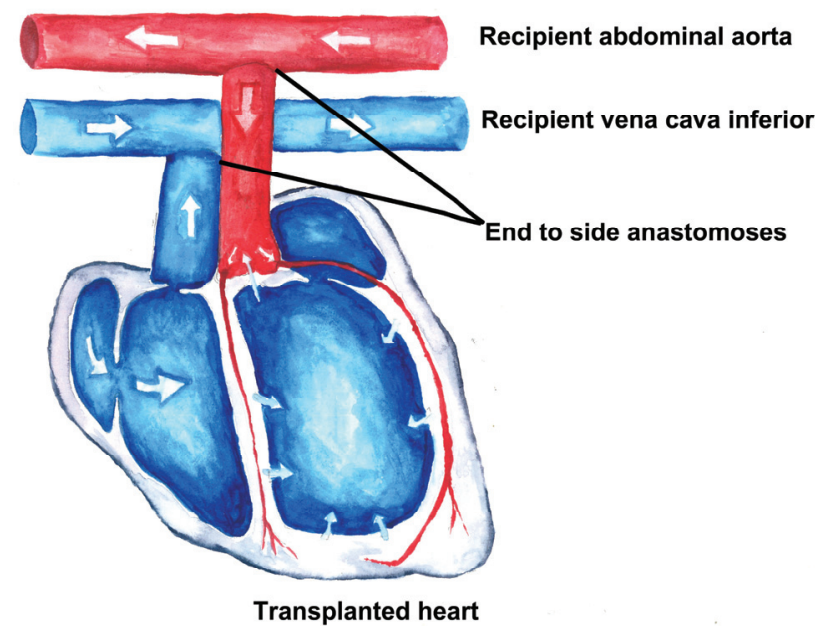

Fig. 1. Schema of heterotopic heart transplantation.

Although extensive research has been done, we are still unable to define the most important pathways leading to unloading-induced cardiac atrophy. Autophagy, apoptosis and various ways of protein degradation have been intensively studied in search for possible targets of future therapy (Razeghi et al. 2003, 2007, Schena et al. 2004, Willis et al. 2009, Muranaka et al. 2010, Cao et al. 2013).

Even though cardiac atrophy associated with mechanical unloading has been demonstrated in several clinical trials (Maybaum et al. 2007) and in many experimental works, not only those using the heterotopically transplanted rat heart (Klein et al. 1991, Rakusan et al. 1997, Oriyanhan et al. 2007) but also in different experimental models based on VADs implantation (Kinoshita et al. 1988, 1996), the question of unloading-induced cardiac atrophy remains controversial. Somewhat unexpectedly some clinical trials indicated that, despite a wide array of changes in a human failing heart treated with a VAD (increased microvasculature density, increased fibrosis), no evidence of cardiomyocyte atrophy was found. This conclusion was based on the measurement of cell size, glycogen content (Drakos et al. 2010) and later on the echocardiographic examinations (Drakos et al. 2013).

\section{Pharmacological means of cardiac atrophy alleviation}

Despite the increasing use of mechanical cardiac support in the clinical routine, only a handful of patients reach permanent cardiac recovery. Mechanical unloading is considered to be the main aspect of VAD therapy, however myocardial atrophy often develops, especially as a result of long-term VAD support. Several clinical protocols that maximize the efficacy of VADs as a bridge to recovery have been adopted. They combine the VAD support and pharmacotherapy aimed to enhance reverse remodeling and suppress untoward changes such as atrophy or development of fibrosis. From the perspective of possible impact on atrophic remodeling, the use of adrenergic beta 2 agonists, especially clenbuterol, seems to be very promising.

\section{The value of clenbuterol in suppressing myocardial atrophy during mechanical unloading}

Clenbuterol (-1(4-Amino-3,5-dichlorophenyl)-2(tert-butylamino)ethanol - Fig. 2), a beta2-adrenergic receptor agonist, was first introduced into medical practice for treatment of asthma (Xydas et al. 2006). In 1992, the anabolic effect of this substance on the skeletal muscle was discovered (Choo et al. 1992). Subsequent studies showed that clenbuterol led to hypertrophy of not only the skeletal muscles but also of the cardiac muscle in rats (Petrou et al. 1995). When the physiological muscle hypertrophy resulting from clenbuterol administration was established, this selective beta-2 agonist came into focus as a possible treatment of cardiac atrophy (Wong et al. 1998). In addition to the hypertrophy inducing properties, 
clenbuterol is known to affect cardiac function, gene and protein expression, excitation-contraction coupling, and cellular metabolism. The favorable effect in cardiac atrophy, (the main factor that limits recovery) formed the rationale for its use in patients with VAD support to improve the recovery rate (Yacoub 2001).

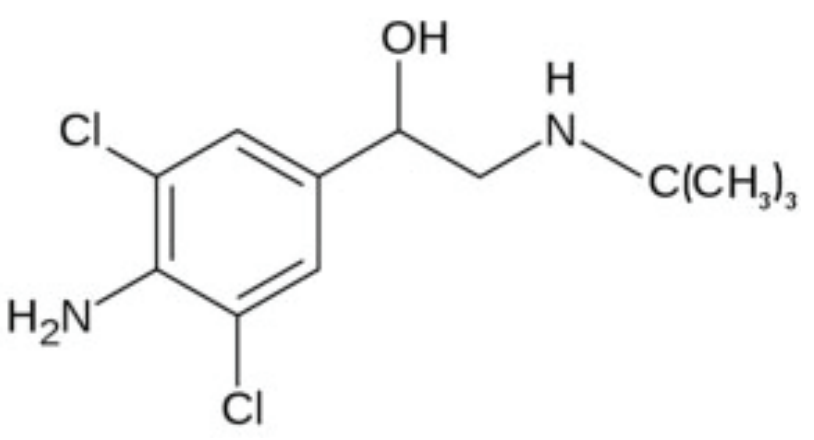

Fig. 2. Clenbuterol.

The beneficial effect of clenbuterol was subsequently supported by the spectacular results achieved by the Harefield group. The combined pharmacotherapy (clenbuterol, angiotensin-converting enzyme inhibitors, beta1-selective antagonists, and spironolactone) which they used during VAD treatment of patients with nonischemic cardiomyopathy allowed the mechanical support explantation in 10 out of 15 patients (Hon et al. 2003, Birks et al. 2006). More recent prospective trials have also produced results favoring the use of clenbuterol. Authors started to administer clenbuterol during the second stage of pharmacological therapy. The initial dose was $40 \mu \mathrm{g}$ twice daily and it was increased to $700 \mu \mathrm{g}$ three times daily. When the Harefield protocol was followed, weaning from continuous-flow mechanical cardiac support was possible in $63.2 \%$ of the patients (Birks et al. 2011). In contrast, patients receiving an equivalent combined therapy but without clenbuterol, reached recovery in $18 \%$ of the cases only. Unsatisfactory results are generally achieved in cases of ischemic cardiomyopathy, where the rate of recovery is only $1 \%$ (Dandel et al. 2011).

Notwithstanding the value of the abovementioned observations, the precise role of clenbuterol in the recovery process remains unclear. Heterotopic abdominal heart transplantation in rats represents an ideal option for a detailed study of how clenbuterol acts in unloaded myocardium. The most significant changes associated with clenbuterol treatment are listed in the following section.
Effects on cardiomyocyte size, contractility and whole ventricular function in experimental models

Clenbuterol limits unloading-induced reduction of cardiomyocyte size in heterotopically transplanted hearts where heart failure had been previously induced by left coronary artery ligation. Clenbuterol administration significantly slowed the decline of cell size, which was registered after mechanical heart unloading (Soppa et al. 2008). No similar effect was found after combining the mechanical unloading with clenbuterol treatment in a normal heart (Tsuneyoshi et al. 2005). This result suggests different regulatory pathways in normal heart and ischemic cardiomyopathy, which may help define possible targets of clenbuterol treatment. Further studies are required to elucidate if clenbuterol administration is beneficial when used during periods longer than in the studies mentioned above ( 1 and 2 weeks). Research into the effect of clenbuterol itself (without mechanical unloading) on the myocardial failure which follows left anterior descending coronary artery ligation confirmed the drug's anabolic potential as reflected by a significant increase of the heart weight (Xydas et al. 2006).

Ischemic cardiomyopathy induces impairment of cardiomyocyte contractility which remains unaffected by mechanical unloading alone. Clenbuterol treatment, in itself or combined with mechanical unloading, significantly improved cell contractility (Soppa et al. 2008).

Clenbuterol-associated functional recovery enhancement during mechanical unloading was demonstrated either in the echocardiographic data or in ex vivo pressure-volume relationship studies (Soppa et al. 2008). In contrast, no significant difference in papillary muscle function was found in a healthy, mechanically unloaded heart after clenbuterol administration (Tsuneyoshi et al. 2005). There was also no favorable effect of clenbuterol alone on the functional recovery of the heart as reflected by echocardiographic data (Xydas et al. 2006).

\section{Effects on myocardial apoptosis in experimental models}

Increased myocardial apoptosis during mechanical unloading has been reported (Schena et al. 2004, Tsuneyoshi et al. 2005). In mechanically unloaded healthy hearts, there were no significant changes in apoptosis markers connected with clenbuterol administration. Nevertheless, the expression of caspase-3 in the unloaded heart tended to decrease in the clenbuterol group (Tsuneyoshi et al. 2005). Other 
experimental studies proved, in a rat ischemic heart model, that beta2-adrenergic stimulation protects myocytes from apoptosis (Ahmet et al. 2004). It is also believed that, in contrast to the antiapoptotic effect of beta2 agonists, beta1-adrenergic receptor (beta1-AR) stimulation is proapoptotic. This evidence was derived from a study in which clenbuterol and metoprolol (beta1-antagonist) treatment, both alone and in combination, led to decreased apoptosis levels in the ischemic heart failure rat model. Remarkably, effects of the combined treatment with clenbuterol and metoprolol were additive (Xydas et al. 2006). Nevertheless, the usefulness of clenbuterol administration remains controversial. Necrosis and a dose-dependent, clenbuterol-induced myocardial apoptosis mediated by beta1-AR have been reported (Burniston et al. 2005).

\section{Other beneficial effects}

Combination of clenbuterol and mechanical unloading normalized the deranged cardiomyocyte calcium cycling. Clenbuterol alone normalized the depressed myofilament sensitivity to calcium in ischemic cardiomyopathy. Consistent data have come also from studies of the mechanical unloading of the normal heart, where impaired expression of calcium ATPase 2a(SERCA2a) in myocardial sarcoplasmic reticulum was found to be improved in the clenbuterol-treated animals (Tsuneyoshi et al. 2005). The importance of efficient calcium cycling for cardiac contractile function is widely known, and many trials report its impairment in the failing heart. Changes in the excitation-contraction coupling and especially in the handling of sarcoplasmic reticulum calcium play a key role in clinical recovery after VAD therapy in humans (Terracciano et al. 2004, Ogletree et al. 2010). Moreover, clenbuterol and mechanical unloading normalized the prolonged action potential duration in the rat model of heart failure (Soppa et al. 2008).

Notwithstanding many uncertainties and reservations concerning the mechanism of action and therapeutic value of clenbuterol, no other of the drugs studied has so far been found to possess a comparable anti-atrophic potential.

\section{Mechanical principles influencing cardiac atrophy}

Cardiac atrophy is a complex and highly regulated phenomenon involving many signaling pathways, and consists of a shift in the balance of simultaneous protein synthesis and degradation in favor of the catabolic processes. Because of cardiac plasticity, disuse atrophy can develop whenever the cardiac load declines for a critical period of time (Mann et al. 2012).

The easiest way of restoring the balance and revert the atrophy should be the reloading of the myocardium. Unfortunately, this is usually difficult in clinical practice because patients could be dependent on cardiac output established by VADs, so that none of the organ systems will suffer from hypoperfusion. This is the main reason why the patient's left, right, or both ventricles are usually highly mechanically unloaded. An analogous approach to cardiac reloading was, to a limited extent, used by the Berlin group in their bridge to recovery protocol (Dandel et al. 2011). All patients on VADs were treated with beta blockers (metoprolol, carvedilol), ACE-inhibitors (enalapril, ramipril, or lisinopril), aldosterone antagonists (spironolactone), loop diuretics (furosemide) and digitalis. After the detection of cardiac improvement, the doses of ACE-inhibitors and diuretics were reduced to increase diastolic pressure and thus increase the afterload. As has been previously mentioned, the recovery rate in their group of patients was $18 \%$ (Dandel et al. 2011).

\section{Mechanical principles influencing cardiac atrophy in experimental models}

Basic research to examine changes following unloading and reloading has been performed on various experimental models.

Experimental studies confirmed that the heart size and growth are determined, in large part, by the volume loading of the heart. Investigators used a well-established rat abdominal heterotopic heart transplantation model in which, as previously described, disuse atrophy peaks at 14 days (Klein et al. 1990). They increased the left ventricular load in the transplant by inserting a cannula into its aortic orifice to induce valvular incompetence and stenosis, and they observed significant cardiac mass increase (Korecky and Masika 1991). Subsequent experiments proved that isovolumic loading of the left ventricle by means of placing the isovolumic latex balloon into the left ventricle prevents atrophy of the heterotopically transplanted rat heart. Fourteen days after surgery, the authors registered an increased left ventricular weight and a higher rate of protein synthesis in loaded ventricles in comparison to 
the control group of heterotopically transplanted hearts. Thus they presented evidence on the importance of cardiac work for the regulation of cardiac growth (Klein et al. 1991).

In accordance with previous works on the subject, the effect of load on atrophy and contractile function in a heart transplant preparation in rats was described. The loaded group of heterotopically transplanted hearts was produced by a modified surgical technique (left atrium was anastomosed to the inferior vena cava, which was then ligated proximally to divert distal venous flow to the left ventricle of the transplanted heart). Loaded hearts evinced a higher left ventricular developed tension, higher left ventricular volume, and no significant weight loss, in comparison to the unloaded, conventionally transplanted hearts seven days after transplantation (Galiananes et al. 1995).

Some investigators tried to elucidate the extent to which the cardiac atrophy could be reversed after reloading. In a relevant study, a discrete portion of cat myocardium was unloaded (a single right ventricular papillary muscle); seven days later, the muscle was reloaded again by attaching its apex to the free ventricular wall. During one week of reloading, all ultrastructural attributes of the past atrophy returned to normal (e.g. cardiomyocyte cross-sectional area and volume density of the mitochondria), and the depressed contractile function returned to the normal state after 14 days of reloading. This study demonstrated cardiac plasticity in adult mammalian myocardium (Thompson et al. 1984).

Another investigation was aimed at a detailed description of heart reloading after a period of mechanical unloading, so modified animal model that included the removal of the left ventricular assist device was introduced. Heterotopically transplanted hearts were unloaded for two weeks and then reloaded by discrete surgical procedure. The donor's right pulmonary artery was anastomosed to the recipient's abdominal aorta for another two weeks. As a result, the left ventricular weights and volumes increased and almost approached normal heart values. This model also demonstrated cardiac plasticity in healthy myocardium. A similar approach can be used for the evaluation of adjunctive interventions in order to facilitate successful VAD weaning (Mizuno et al. 2005).

To find a strategy to reverse disuse atrophy, the ventricular pacing was examined. The heterotopically transplanted rat hearts were continuously paced (420 beats/min) and left ventricular weight and protein content were significantly elevated only during the first week. After two weeks, there were no significant difference between the paced and the non-paced groups ofheterotopically transplanted hearts (Geenen et al. 1994). On the basis of the above results, it is assumed that cardiac growth is mostly dependent on a cardiac load.

\section{Conclusions}

Little is known about specific mechanisms governing the heart unloading-induced cardiac atrophy and about the exact ultrastructural changes in cardiomyocytes, and even less is known about possible therapeutical interventions affecting heart atrophy. Mechanical unloading-induced atrophy undoubtedly represents one of the main obstacles preventing achievement of cardiac recovery.

In this review, we summarized important aspects of the development of cardiac atrophy in humans, and we also tried to find the most significant linkages to observations made in experimental models. The major aim was to compile currently known possible means which might counteract cardiac atrophy during mechanical unloading.

Out of many pharmacological agents, only clenbuterol, a selective beta2 agonist has been found to have a significant beneficial effect on unloading-induced atrophy. In an experimental model of ischemic cardiomyopathy, clenbuterol also helped maintain cardiomyocyte contractility. Many other beneficial effects of clenbuterol on mechanically unloaded failing myocardium have been reported. In contrast, no significant changes in atrophy progression have been reported after clenbuterol administration in normal heart mechanical unloading scenarios. Currently, clenbuterol is the only agent that affects cardiac atrophy, and it has also been used with favorable effect in clinical trials.

Mechanical means of atrophy alleviation seem to be very potent and promising. Various experiments proved a very strong dependence of cardiac atrophy on cardiac load. However, it seems still not feasible to apply this approach in the clinical praxis. Nevertheless, the relevant experimental studies potentially open a way for new technical solutions in VAD development. A number of supplemental strategies, such as patient exercise programs, could also be helpful. One very important aspect of future successful recovery from heart failure is an appropriate timing of VAD therapy in order to 
diminish irreversible damage of the myocardium.

Analysis of myocardial tissue samples obtained from recovered patients has revealed many differences compared with the samples from their non-recovered counterparts. This research could establish a base for novel strategies such as direct gene or cell therapy.

\section{Conflict of Interest}

There is no conflict of interest.

\section{Acknowledgements}

This study was supported by project of the Ministry of Health of the Czech Republic within the project for the development of research organization 00023001 (IKEM) - institutional support. The Center for Experimental Medicine (IKEM) received financial support from the European Commission within the Operational Program Prague-Competitiveness; project "CEVKOON" (\#CZ.2.16/3.1.00/22126).

\section{References}

ABOTT CP, LINDSEY ES, CREECH O, DEWITT CW: A technique for heart transplantation in the rat. Arch Surg 89: 645-652, 1964.

AHMET I, KRAWCZYK M, HELLER P, MOON C, LAKATTA EG, TALAN MI: Beneficial effects of chronic pharmacological manipulation of beta-adrenoreceptor subtype signaling in rodent dilated ischemic cardiomyopathy. Circulation 110: 1083-1090, 2004.

BASKIN KB, TAEGTMEYER H: Taking pressure off the heart: The ins and outs of atrophic remodelling. Cardiovasc Res 90: 243-250, 2011.

BIRKS EJ, TANSLEY PD, HARDY J, GEORGE RS, BOWLES CHT, BURKE M, BANNER NR, KHAGHANI A, YACOUB MH: Left ventricular assist device and drug therapy for the reversal of heart failure. New Engl J Med 355: 1873-1884, 2006.

BIRKS EJ, GEORGE RS, HEDGER M, BAHRAMI T, WILTON P, BOWLES CHT, WEBB C, BOUGARD R, AMRANI R, YACOUB MH, DREYFUS G, KHAGHANI A: Reversal of severe heart failure with a continuous-flow left ventricular assist device and pharmacological therapy: A prospective study. Circulation 123: 381-390, 2011.

BURNISTON JG, TAN LB, GOLDSPINK DF: Beta2-adrenergic receptor stimulation in vivo induces apoptosis in the rat heart and soleus muscle. J Appl Physiol 98: 1379-1386, 2005.

BUTLER CR, JUGDUTT BI: The paradox of left ventricular device unloading and myocardial recovery in end-stage dilated cardiomyopathy: implications for heart failure in the elderly. Heart Fail Rev 17: 615-633, 2012.

CAO DJ, JIANG N, BLAGG A, JOHNSTONE JL, GONDALIA R, OH M, LUO X, YANG KC, SHELTON JM, ROTHERMEL BA, GILLETTE TG, DORN GW, HILL JA: Mechanical unloading activates FoxO3 to trigger Bnip3-dependent cardiomyocyte atrophy. J Am Heart Assoc 2: e000016, 2013.

CHOO JJ, HORAN MA, LITTLE RA: Anabolic effects on skeletal muscle are mediated by beta2-adrenoceptor activation. Am J Physiol 263: E50-E56, 1992.

COHN JN, FERRARI R, SHARPE N: Cardiac remodeling - concepts and clinical implications: a consensus paper from an international forum on remodeling. Behalf of an International Forum on Cardiac Remodeling. J Am Coll Cardiol 35: 569-582, 2000.

CORRY RJ, WINN HJ, RUSSEL PS: Heart transplantation in congenic strains of mice. Transplant Proc 5: 733-735, 1973.

DANDEL M, WENG Y, SINIAWSKI H, STEPANENKO A, KRABATSCH T, POTAPOV E, LEHMKUHL HB, KNOSALLA C, HETZER R: Heart failure reversal by ventricular unloading in patients with chronic cardiomyopathy: criteria for weaning from ventricular assist devices. Eur Heart J 32: 1148-1160, 2011.

DEBAKEY ME: The Odyssey of the artificial heart. Artif Organs 24: 405-411, 2000.

DRAKOS SG, TERROVITIS JV, ANASTASIOU-NANA MI, NANAS JN: Reverse remodeling during long-term mechanical unloading of the left ventricle. J Mol Cell Cardiol 43: 231-242, 2007. 
DRAKOS SG, KFOURY AG, HAMMOND EH, REID BB, REVELO MP, RASMUSSON BY, WHITEHEAD KJ, SALAMA ME, SELZMAN CH, STEHLIK J, CLAYSON SE, BRISTOW MR, RENLUND DG, LI DY: Impact of mechanical unloading on microvasculature and associated central remodeling features of the failing human heart. J Am Coll Cardiol 56: 382-391, 2010.

DRAKOS SG, KHOURY AG, SELZMAN CH, VERMA DR, NANAS JN, LI DY, STEHLIK J: Left ventricular assist device unloading effects on myocardial structure and function: Current status of the field and call for action. Curr Opin Cardiol 26: 245-255, 2011 a.

DRAKOS SG, TERROVITIS JV, NANAS JN, CHARITOS EI, NTALIAMIS AS, MALLIARAS KG, DIAKOS N, KOUDOUMAS D, THEODOROPOULOS S, YACOUB MH, ANASTASIOU-NANA MI: Reverse electrophysiologic remodeling after cardiac mechanical unloading for end-stage nonischemic cardiomyopathy. Ann Thorac Surg 91: 764-769, 2011 b.

DRAKOS SG, WEVER-PINZON O, SELZMAN CH, GILBERT EM, ALHARETHI R, REID BB, SAIDI A, DIAKOS NA, STOKER S, DAVIS ES, MOVSESIAN M, LI DY, STEHLIK J, KFOURY AG: Magnitude and time course of changes induced by continuous-flow left ventricular assist device unloading in chronic heart failure. J Am Col Cardiol 61: 1985-1994, 2013.

FELKIN LE, LARA-PEZZI EA, HALL JL, BIRKS EJ, BARTON PJR: Reverse remodelling and recovery from heart failure are associated with complex pattern of gene expression. J Cardiovasc Trans Res 4: 321-331, 2011.

FRAZIER OH, BENEDICT CR, RADOVANCEVIC B, BICK RJ, CAPEK P, SPRINGER WE, MACRIS MP, DELGADO R, BUJA LM: Improved left ventricular function after chronic left ventricular unloading. Ann Thorac Surg 62: 675-682, 1996.

GALIANANES M, ZHAI X, HEARSE DJ: The effect of load on atrophy, myosin isoform shifts and contractile function: studies in a novel rat heart transplant preparation. J Mol Cell Cardiol 27: 407-417, 1995.

GEENEN DL, MALHOTRA A, BUTTRICK PM, SCHEUER J: Ventricular pacing attenuates but does not reverse cardiac atrophy and an isomyosin shift in the rat heart. Am J Physiol 267: H2149-H2154, 1994.

HEERDT PM, HOLMES JW, CAI B, BARBONE A, MADIGAN JD, REIKEN S, LEE DL, OZ MC, MARKS AR, BURKHOFF D: Chronic unloading by left ventricular assist device reverses contractile dysfunction and alters gene expression in end-stage heart failure. Circulation 102: 2713-2719, 2000.

HELLERSTEIN HK, SANTIAGO-STEVENSON D: Atrophy of the heart: a correlative study of eighty-five proved cases. Circulation 1: 93-126, 1950.

HON JK, YACOUB MH: Bridge to recovery with the use of left ventricular assist device and clenbuterol. Ann Thorac Surg 75: S36-S41, 2003.

IBRAHIM M, NAVARATNARAJAH M, SIEDLECKA U, RAO CH, DIAS P, MOSHOV AV, GORELIK J, YACOUB MH, TERRACCIANO CM: Mechanical unloading reverses transverse tubule remodelling and normalizes local calcium-induced calcium release in a rodent model of heart failure. Eur J Heart Fail 14: 571-580, 2012.

IBRAHIM M, NAVARATNARAJAH M, KUKADIA P, RAO CH, SIEDLECKA U, CARTLEDGE JE, SOPPA GK, VAN DOORN C, YACOUB MH, TERRACCIANO CM: Heterotopic abdominal heart transplantation in rats for functional studies of ventricular unloading. J Surg Res 179: E31-E39, 2013.

KINOSHITA M, TAKANO H, TAENAKA Y, MORI H, TAKAICHI S, NODA H, TATSUMI E, YAGURA A, SEKII H, AKATSU T: Cardiac disuse atrophy during LVAD pumping. ASAIO Trans 34: 208-212, 1988.

KINOSHITA M, TAKANO H, TAKAICHI S, TAENAKA Y, NAKATANI T: Influence of prolonged ventricular assistance on myocardial histopathology in intact heart. Ann Thor Surg 61: 640-645, 1996.

KLEIN I, HONG C, SCHREIBER SS: Cardiac atrophy in the heterotopically transplanted rat heart: in vitro protein synthesis. J Mol Cell Cardiol 22: 461-468, 1990.

KLEIN I, HONG C, SCHREIBER SS: Isovolumic loading prevents atrophy of the heterotopically transplanted rat heart. Circ Res 69: 1421-1425, 1991.

KLEIN I, SAMAREL AM, WELIKSON R, HONG C: Heterotopic cardiac transplantation decreases the capacity for rat myocardial protein synthesis. Circ Res 68: 1100-1107, 1991.

KLOTZ S, JAN DANSER AH, BURHOFF D: Impact of left ventricular assist device (LVAD) support on the cardiac reverse remodeling process. Prog Biophys Mol Bio 97: 479-496, 2008. 
KORECKY B, MASIKA M: Direct effect of increased hemodynamic load on cardiac mass. Circ Res 68: 1174-1178, 1991.

MANN DL, BRISTOL MR: Mechanisms and models in heart failure: The biomechanics model and beyond. Circulation 111: 2837-2849, 2005.

MANN DL, BARGER PM, BURKHOFF D: Myocardial recovery and the failing heart. $J$ Am Coll Cardiol 60: 24652472, 2012.

MANN FC, PRIESTLEY JT, MARKOWITZ J, YATER WM: Transplantation of the intact mammalian heart. Arch Surg 26: 219-224, 1933.

MAYBAUM S, MANCINI D, XYDAS S, STARLING RC, AARONSON K, PAGANI FD, MILLER LW, MARGULIES K, MCREE S, FRAZIER OH, TORRE-AMIONE G: Cardiac improvement during mechanical circulatory support: a prospective multicenter study of the LVAD working group. Circulation 115: 2497-2505, 2007.

MIZUNO T, WEISEL RD, LI RK: Reloading the heart: a new animal model of left ventricular assist device removal. J Thorac Cardiovasc Surg 130: 99-106, 2005.

MURANAKA H, MARUI A, TSUKASHITA M, WANG J, NAKANO J, IKEDA T, SAKATA R: Prolonged mechanical unloading preserves myocardial contractility but impairs relaxation in rat heart of dilated cardiomyopathy accompanied by myocardial stiffness and apoptosis. J Thor Cardiovasc Surg 140: 916-922, 2010.

OGLETREE ML, SWEET WE, TALERICO C, KLECKA ME, YOUNG JB, SMERIDA NG, STARLING RC, MORAVEC CS: Duration of left ventricular assist device support: effects on abnormal calcium cycling and functional recovery in the failing human heart. $J$ Heart Lung Transplant 29: 554-561, 2010.

ORIYANHAN W, TSUNEYOSHI H, NISHINA T, MATSUOKA S, IKEDA T, KOMEDA M: Determination of optimal duration of mechanical unloading for failing hearts to achieve bridge to recovery in a rat heterotopic heart transplantation model. J Heart Lung Transplant 26: 16-23, 2007.

PERHONEN MA, FRANCO F, LANE LD, BUCKEY JC, BLOMQVIST CG, ZERWEKH JE, PESHOCK RM, WEATHERALL PT, LEVINE BD: Cardiac atrophy after bed rest and spaceflight. $J$ Appl Physiol 91: 645-653, 2001.

PETROU M, WYNNE DG, BOHELER KR, YACOUB MH: Clenbuterol induces hypertrophy of the latissimus dorsi muscle and heart in the rat with molecular and phenotypic changes. Circulation 92: 483-489, 1995.

RAKUSAN K, HERON MI, KOLAR F, KORECKY B: Transplantation-induced atrophy of normal and hypertrophic rat hearts: effect on cardiac myocytes and capillaries. J Mol Cell Cardiol 29: 1045-1054, 1997.

RAZEGHI P, SHARMA S, YING J, LI Y, STEPKOWSKI S, REID MB, TAEGTMEYER H: Atrophic remodeling of the heart in vivo simultaneously activates pathways of protein synthesis and degradation. Circulation 108: 2536-2541, 2003.

RAZEGHI P, VOLPINI KC, WANG M, YOUKER KA, STEPKOWSKI S, TAEGTMEYER H: Mechanical unloading of the heart activates the calpain system. $J$ Mol Cell Cardiol 42: 449-452, 2007.

RODRIGUE-WAY A, BURHOFF D, GEESAMAN BJ, GOLDEN BS, XU J, POLLMAN J, DONOGHUE M, JEYSEELAN R, HOUSER S, BREITBART RE, MARKS A, ACTON S: Sarcomeric genes involved in reverse remodeling of the heart during left ventricular assist device support. $J$ Heart Lung Transplant 24: 73-80, 2005.

RUZZA A, VESPIGIANI R, CZER LS, DE ROBERTIS M, WU GN, TRENTO A: Heterotopic heart transplantation in rats: improved anesthetic and surgical technique. Transplant Proc 42: 3828-3832, 2010.

SCHENA S, KURIMOTO Y, FUKADA J, TACK I, RUIZ P, PANG M, STRIKER LJ, AITOUCHE A, PHAM SM: Effects of ventricular unloading on apoptosis and atrophy of cardiac myocytes. $J$ Surg Res 120: 119-126, 2004.

SOPPA GK, LEE J, STAGG MA, FELKIN LE, BARTON PJ, SIEDLECKA U, YOUSSEF S, YACOUB MH, TERRACCIANO CM: Role and possible mechanisms of clenbuterol in enhancing reverse remodelling during mechanical unlading in murine heart failure. Cardiovasc Res 77: 695-706, 2008.

SOPPA GKR, BARTON PJR, TERRACCIANO CMN, YACOUB MH: Left ventricular assist device-induced molecular changes in the failing myocardium. Curr Opin Cardiol 23: 206-218, 2008. 
TERRACCIANO CMN, HARDING SE, ADAMSON S, KOBAN M, TANSLEY P, BIRKS EJ, BARTON PJR, YACOUB MH: Changes in sarcolemal $\mathrm{Ca}$ entry and sarcoplasmatic reticulum $\mathrm{Ca}$ content in ventricular myocytes from patients with end-stage heart failure following myocardial recovery after combined pharmacological and ventricular assist device therapy. Eur Heart J 24: 1329-1339, 2003.

TERRACCIANO CMN, HARDY J, BIRKS EJ, KHAGHANI A, BANNER NR, YACOUB MH: Clinical recovery from end-stage heart failure using left-ventricular assist device and pharmacological therapy correlates with increased sarcoplasmic reticulum calcium content but not with regression of cellular hypertrophy. Circulation 109: 2263-2265, 2004.

THOMPSON EW, MARINO TA, UBOH E, KENT RL, COOPER G: Atropy reversal and cardiocyte redifferentiation in reloaded cat myocardium. Circ Res 54: 367-377, 1984.

TSUNEYOSHI H, ORIYANHAN W, KANEMITSU H, SHIINA R, NISHINA T, MATSUOKA S, IKEDA T, KOMEDA M: Does the beta2-agonist clenbuterol help to maintain myocardial potential to recover during mechanical unloading? Circulation 112: I51-I56, 2005.

WILLIS MS, ROJAS M, LI L, SELZMAN CH, TANG R, STANSFIELD WE, RODRIGUEZ JE, GLASS DJ, PATTERSON C: Muscle ring finger 1 mediates cardiac atrophy in vivo. Am J Physiol Heart Circ Physiol 296: 997-1006, 2009.

WONG K, BOHELER KR, BISHOP J, PERTOU M: Clenbuterol induces cardiac hypertrophy with normal functional, morphological and molecular features. Cardiovasc Res 37: 115-122, 1998.

XYDAS S, KHERANI AR, CHANG JS, KLOTZ S, HAY I, MUTRIE CJ, MOSS GW, GU A SCHULMAN AR, GAO D, HU D, WU EX, WEI C, OZ MC, WANG J: Beta2-adrenergic stimulation attenuates left ventricular remodeling, decreases apoptosis, and improves calcium homeostasis in a rodent model of ischemic cardiomyopathy. J Phar Exp Ther 317: 553-561, 2006.

YACOUB MH: A novel strategy to maximize the efficacy of left ventricular assist devices as a bridge to recovery. Eur Heart J 22: 534-540, 2001. 